\title{
DEPENDÊNCIA EPISTÊMICA, TESTEMUNHO E GETTIERIZAÇÃO
}

Epistemic dependence, testimony, and gettierization

Dependencia epistémica, testimonio e gettierização

J. R. Fet $\mathrm{t}^{1}$

Pontifícia Universidade Católica do Rio Grande do Sul, Porto Alegre, RS, Brasil.

\section{Resumo}

O objetivo deste ensaio é examinar a proposta de Sandy Goldberg, segundo a qual há divisão de trabalho epistêmico em certos processos de aquisição de conhecimento ao menos em se tratando de conhecimento testemunhal. Goldberg propõe mostrar a veracidade desta alegação salientando a nossa dependência epistêmica em relação a outros indivíduos, ou mesmo comunidades inteiras. Nós, então, vamos propor o tratamento de um famoso caso tipo-Gettier que, segundo Gilbert Harman, revelaria algumas dimensões sociais do conhecimento. Por fim, nós esperamos tirar algumas lições da explicação oferecida por Goldberg, dentre as quais a mais importante a ser tomada é que, havendo tal divisão de trabalho epistêmico em processos de aquisição de conhecimento, muitas vezes, não são apenas as propriedades epistêmicas do sujeito que determinam a sua posse de conhecimento ou ignorância, de modo que o conhecimento é mais social do que individual em se tratando de uma ampla gama de casos.

Palavras-chave: Dependência Epistêmica. Testemunho. Gettierização. Sandy Goldberg. Gilbert Harman.

Doutor em Filosofia pela Pontifícia Universidade Católica do Rio Grande do Sul (PUCRS), Porto Alegre, RS, Brasil. ORCID: http://orcid.org/oooo-0001-5585-6293. E-mail: jrfetto1@gmail.com 


\begin{abstract}
The aim of this essay is to examine Sandy Goldberg's proposal, according to which there is some division of epistemic labor in certain processes of knowledge acquisition - at least in the acquisition of testimonial knowledge. Goldberg intends to show why this is true by highlighting our epistemic dependence on other people, or even on entire communities. With Goldberg's proposal in mind, we will try to handle a famous Gettiertype case which, according to Gilbert Harman, unveils some social aspects of knowledge. Lastly, we hope to take some lessons from Goldberg's proposal, among which the most important is that, if there is in fact division of epistemic labor in processes of knowledge acquisition, then in many situations the subject's epistemic properties are not the only decisive factors relevant to verify whether or not she has knowledge, thus showing that knowledge is more social than individual when it comes to a vast range of cases.
\end{abstract}

Keywords: Epistemic Dependence. Testimony. Gettierization. Sandy Goldberg. Gilbert Harman.

\title{
Resumen
}

El objetivo de este ensayo es examinar la propuesta de Sandy Goldberg, según la cual existe una división del trabajo epistémico en ciertos procesos de adquisición de conocimientos, al menos en se tratanto del conocimiento testimonial. Goldberg propone mostrar la veracidad de esta alegación destacando la nuestra dependencia epistémica en relación a otros individuos, o incluso comunidades enteras. Nosotros, entonces, proponemos el tratamiento de un famoso caso tipo Gettier, según Gilbert Harman, que revelaría algunas dimensiones sociales del conocimiento. Por último, esperamos tomar algunas lecciones de la explicación ofrecida por Goldberg, entre las que la más importante a tomada es que, teniendo tal división del trabajo epistémico en los procesos de adquisición de conocimiento, a menudo, no son sólo las propiedades Epistémica del sujeto que determinan su posesión de conocimiento o ignorancia, por lo que el conocimiento es más social que individual en se tratando de una amplia gama de casos.

Palabras clave: Dependencia epistémica. Testimonio. Gettierização. Sandy Goldberg. Gilbert Harman.

\section{Introdução}

O objetivo deste ensaio é examinar a proposta de Sandy Goldberg, segundo a qual há divisão de trabalho epistêmico em certos processos de aquisição de conhecimento - ao menos em se tratando de conhecimento testemunhal. Goldberg propõe mostrar a veracidade dessa alegação salientando a nossa 
dependência epistêmica em relação a outros indivíduos, ou mesmo comunidades inteiras. Nós, então, vamos propor o tratamento de um famoso caso tipo-Gettier que, segundo Gilbert Harman, revelaria algumas dimensões sociais do conhecimento. Por fim, nós esperamos tirar algumas lições da explicação oferecida por Goldberg, dentre as quais a mais importante a ser tomada é que, havendo tal divisão de trabalho epistêmico em processos de aquisição de conhecimento, muitas vezes, não são apenas as propriedades epistêmicas do sujeito (ou, se preferirmos, seu status epistêmico) que determinam a sua posse de conhecimento ou ignorância - às vezes, é impossível saber sozinho.

\section{Dependência epistêmica direta}

O status epistêmico de um sujeito $S$ em relação a uma crença $P$ pode ser afetado por características sobre os demais membros da comunidade de $\mathrm{S}$ ? Pode haver alguma dependência epistêmica da crença $\mathrm{P}$ de $\mathrm{S}$ em relação às propriedades epistêmicas dos sujeitos $S_{1}, S_{2}, \ldots, S_{n}$, que compõem a comunidade na qual $S$ está inserido? Se sim, em que sentido o que um indivíduo crê, ou o que ele crê justificadamente, ou o que ele sabe é afetado por aquilo que outros indivíduos creem, creem justificadamente, ou sabem? Sandy Goldberg propôs uma explicação para esse fenômeno, que passou a chamar-se "dependência epistêmica", que, segundo ele, suporta a tese de que há uma divisão do trabalho epistêmico presente em certos processos de aquisição de conhecimento e justificação. A hipótese de Goldberg é basicamente a seguinte:

Para todos os sujeitos epistêmicos $\mathrm{S}$ e algumas das atitudes doxásticas $D$ de $S$, as propriedades epistêmicas de $D$ dependem, em parte, de fatos sobre membros da comunidade de $S$, e especialmente de fatos em relação à perspectiva epistêmica e/ou às disposições epistemicamente relevantes de um ou mais desses membros. ${ }^{2}$

\footnotetext{
2 Do original: For all epistemic subjects $S$ and some of S's doxastic attitudes $D$, the epistemic properties of $D$ depend in part on facts about members of S's community, and in particular on facts regarding the epistemic perspective(s) and/or epistemically-relevant disposition(s) of one or more of these members (GOLDBERG, 2011, p. 112, tradução nossa).
} 
A assim chamada "perspectiva epistêmica" constitui o conjunto de características relevantes para determinar o caráter epistêmico (isto é, a qualidade) do sistema de crenças de um sujeito em um dado tempo. E as assim chamadas "disposições epistemicamente relevantes" são as disposições manifestadas em contextos de investigação e interação, bem como aquelas manifestadas por meio da comunicação de uma informação. ${ }^{3}$

Esse fenômeno, sugere Goldberg, pode ser explicado por meio da nossa dependência epistêmica em relação a outros indivíduos, ou mesmo comunidades inteiras. Segundo ele, há duas formas distintas em que o status epistêmico de um sujeito $S$ em relação a uma crença $P$ pode depender das propriedades epistêmicas de outros indivíduos ou comunidades. São eles:

[DIR]: Um sujeito $S_{1}$ depende diretamente (epistemicamente) de outro sujeito $S_{2}$ com respeito à atitude doxástica $D$ de $S_{1}$ quando a seguinte condição se dá: há variações na perspectiva epistêmica de $\mathrm{S}_{2}$ que constituiriam variações nas propriedades epistêmicas de D. ${ }^{4}$

[DIF]: Um sujeito $S_{1}$ depende difusamente (epistemicamente) da sua comunidade $C$ com respeito à sua atitude doxástica $D$ quando a seguinte condição se dá: há variações nas práticas dos membros de C, e variações nos estados e disposições desses membros, que constituiriam variações nas propriedades epistêmicas de D; e esse efeito permanece mesmo depois de subtrairmos os efeitos de qualquer dependência epistêmica direta que $S_{1}$ exibe com respeito a D. ${ }^{5}$

3 Cf. GOLDBERG, 2011, p. 112-113.

${ }_{4}$ Do original: A subject $\mathrm{S} 1$ directly (epistemically) depends on another subject $\mathrm{S} 2$ with respect to S1's doxastic attitude D when the following condition holds: there are variations in S2's epistemic perspective that would make for variations in the epistemic properties of D (GOLDBERG, 2011, p. 113, tradução nossa).

5 Do original: A subject S1 diffusely (epistemically) depends on her community $C$ with respect to her doxastic attitude $D$ when the following condition holds: there are variations in the practices of the members of $C$, and variations in the states and dispositions of those members, that would make for variations in the epistemic properties of $D$; and this effect remains even 
Agora, considere novamente a questão que propusemos no início desta seção: De que modo(s) um sujeito $S$ e suas atitudes doxásticas podem depender epistemicamente de outros sujeitos $S_{1}, S_{2}, \ldots, S_{n}$ e suas propriedades epistêmicas? Casos de testemunho manifestam o que Goldberg chama de DIR (dependência epistêmica direta). Nesses casos, a dependência epistêmica é evidenciada pelo fato de que o status epistêmico da crença formada pelo receptor do testemunho depende da qualidade da perspectiva epistêmica da testemunha, a saber, a sua confiabilidade e a qualidade das suas razões para tal crença testemunhal.

Se, por exemplo, $\mathrm{S}_{1}$ diz a $\mathrm{S}_{2}$ que Barack Obama foi presidente dos Estados Unidos, $\mathrm{S}_{2}$ pode ganhar conhecimento por meio do testemunho de $\mathrm{S}_{1}$. Mas isso parece (ao menos para alguns) depender não somente da verdade da proposição testemunhada e das propriedades epistêmicas de $S_{2}$ ao tomar tal testemunho, mas também das propriedades epistêmicas de $S_{1}$. Talvez $S_{2}$ passe a saber que Barack Obama foi presidente dos Estados Unidos somente se $\mathrm{S}_{1}$ sabe o que está dizendo. Se, ao contrário disto, $\mathrm{S}_{1}$ é ignorante sobre aquele fato, e o que é pior, anda afirmando coisas para as quais ele não tem qualquer suporte, parece que a situação epistêmica de $\mathrm{S}_{2}$ é prejudicada. ${ }^{6}$

A dependência epistêmica de $S_{2}$ em relação a $S_{1}$ é manifestada no fato de que a eventual crença de $S_{2}$ na proposição de que Barack Obama foi presidente dos Estados Unidos goza de melhor status epistêmico positivo à medida que a crença de $\mathrm{S}_{1}$ naquela mesma proposição goza de melhor

after we subtract the effects of any direct epistemic dependence $S_{1}$ exhibits with respect to D (GOLDBERG, 2011, p. 113, tradução nossa).

6 A ignorância ou a inconfiabilidade da testemunha podem ser mais claramente vistas como ameaças à aquisição de conhecimento por parte do receptor se as concebermos como derrotadores para a justificação da crença testemunhal do receptor. Um derrotador é, basicamente, uma proposição verdadeira que, se conjugada com a evidência do sujeito para a sua crença-alvo, faria tal crença-alvo injustificada. Imagine as seguintes proposições verdadeiras sobre uma testemunha S que assere que P: "S não sabe que P" e "S é inconfiável quanto a se P". Qualquer uma dessas verdades, se conjugadas com quaisquer razões que o receptor tenha para crer que $P$, fariam tal crença em $P$ injustificada. Isto revela, portanto, por que deveríamos tomar a ignorância ou a inconfiabilidade da testemunha como fatores que impedem o receptor de adquirir conhecimento por meio de tal testemunho asserido por ela. Veja (KLEIN, 1981) para uma explicação da noção de derrotador em epistemologia. 
status epistêmico positivo, tal que se $S_{1}$ sabe aquilo e $S_{2}$ recebe o seu testemunho de modo apropriado, $\mathrm{S}_{2}$ tem tudo para possuir conhecimento. Se, ao contrário, $\mathrm{S}_{1}$ é ignorante sobre aquilo, é difícil ver como $\mathrm{S}_{2}$ pode possuir tal item de conhecimento. Considere, por exemplo, a confiabilidade de $\mathrm{S}_{1}$. Se $\mathrm{S}_{1}$ é inconfiável, mesmo que ele esteja certo agora, em situações contrafactuais próximas ele testemunhará falsidades. Parece-nos que se $\mathrm{S}_{2}$ possui conhecimento, a segurança da crença adquirida é indispensável. E aqui está uma instanciação de DIR, de acordo com a qual a confiabilidade do testemunho de $\mathrm{S}_{1}$ faz parte de sua perspectiva epistêmica e tal perspectiva incide sobre a posse de conhecimento ou ignorância de $\mathrm{S}_{2}{ }^{7.8}$

Aqui é importante fazermos uma nota de cautela sobre a força das alegações que recém fizemos. Como bem observa Goldberg, a dependência epistêmica nos casos de conhecimento testemunhal tem a ver mais diretamente com a tese sobre como o conhecimento de $\mathrm{S}_{2}$ pode ser afetado, ou mesmo impedido, dependendo da situação epistêmica de $\mathrm{S}_{1}$. No entanto, alguns podem alegar que a justificação doxástica de $S_{2}$ não tem a mesma vulnerabilidade às más propriedades epistêmicas de $S_{1}$. Em outras palavras, para alguns, embora o conhecimento seja afetado pela perspectiva epistêmica de outros sujeitos da comunidade, a justificação não é - esta última depende exclusivamente da perspectiva epistêmica do sujeito cognoscente. Há internalistas, para os quais o status justificacional prima facie de uma crença é determinado exclusivamente por estados internos à vida mental do sujeito. Feldman e Conee (2001) são exemplos paradigmáticos de internalistas para os quais estados mentais de terceiros não tem qualquer incidência sobre o

\footnotetext{
7 Veja Lackey (2008), para uma explicação do princípio de segurança e do princípio de sensibilidade aplicados a um ato de testemunho.

8 A segurança e a sensibilidade de uma crença são propriedades que a qualificam epistemicamente, tal que se essa crença for verdadeira, ela não o será por mero acaso (isto é, ela não será acidentalmente verdadeira). Se a crença de que $P$ é segura, então $S$ não facilmente acreditaria falsamente que $P$ - veja SOSA, 1999. Se a crença de que $P$ é sensível, então se $P$ fosse falsa, S não acreditaria que P - veja NOZICK, 1981. As teorias da segurança e da sensibilidade são propostas populares de tratamento ao Problema de Gettier. Veja as suas aplicações nesse debate em Becker (2007).
} 
status justificacional prima facie das crenças de um sujeito. $S_{2}$ pode, assim, estar doxasticamente justificado em crer que Barack Obama foi presidente dos Estados Unidos por fazer uma inferência sobre a alta probabilidade de isso ser verdadeiro dada a sua crença de que $S_{1}$ é confiável e a ausência de qualquer contraevidência para isto, por exemplo. ${ }^{9}$

A Gettierização pode ser um fator explanatório importante aqui. Goldberg observa que nos casos Gettier, embora a justificação doxástica do sujeito seja impecável enquanto bom suporte evidencial, há algo no ambiente que o circunda que o impede de adquirir conhecimento. Lembremo-nos do famoso caso Celeiros Falsos:

S encontra-se no Distrito dos Celeiros Falsos, mas ele não suspeita disso. Todos os celeiros na vizinhança são falsos, exceto o celeiro para o qual S está olhando. Uma vez que este celeiro genuíno e aqueles falsos são indistinguíveis da perspectiva de $S$ e que $S$ não tem qualquer base para pensar que alguma coisa está errada, ele passa a crer veraz e justificadamente que há um celeiro. ${ }^{10}$

Nesse caso, a dependência epistêmica do sujeito em relação ao ambiente no qual ele se encontra explica a impossibilidade da obtenção de conhecimento por parte deste sujeito." É possível que alguns queiram entender a dependência epistêmica nos casos de testemunho como uma

\footnotetext{
9 Se adotarmos a perspectiva antirreducionista em epistemologia do testemunho, nem precisamos exigir do receptor qualquer inferência que leve em conta a confiabilidade do testemunho a fim que a sua crença testemunhal seja considerada justificada. Veja a defesa dessa perspectiva em Audi (1997).

10 Do original: $S$ is in Phony Barn Country, but she doesn't suspect it. All of the barns in the vicinity (the boundaries of the "vicinity" will matter later!) are phony except the barn $\mathrm{S}$ is looking at. Given that the real barn and the phony ones are indistinguishable from S's perspective and that $S$ has no grounds for thinking something is amiss, she comes to believe truly and justifiably that there is a barn (KLEIN, 2012, p. 159, tradução nossa).

"Veja Goldman (1976), para a versão original e o primeiro tratamento do caso dos celeiros falsos na literatura.
} 
circunstância desse tipo mais geral de dependência sobre o ambiente. ${ }^{12}$ Duncan Pritchard (2012), inclusive, sugere que há um tipo de Gettierização cuja característica fundamental é a presença da chamada sorte ambiental que afeta o sujeito. ${ }^{3}$ Porém, Goldberg crê que essa explicação não representa adequadamente a dependência epistêmica presente nos casos de conhecimento testemunhal, pois não é nem de longe óbvio que a confiabilidade de um testemunho é importante apenas como um potencial fator de Gettierização. ${ }^{14}$ Antes, é mais atrativa a ideia de que a importância de tal confiabilidade reflete uma dependência social do sujeito em relação à sua comunidade - isto é, em relação ao que os demais sujeitos que participam da cadeia testemunhal e do contexto epistêmico de $S$ acreditam e sabem, e em relação à confiabilidade dos mesmos nessas circunstâncias.

Interessantemente, mesmo a sugestão de que a justificação doxástica depende exclusivamente da perspectiva epistêmica do indivíduo, enquanto o conhecimento depende também da perspectiva epistêmica de outros, pode ser desafiada. Jennifer Lackey, por exemplo, alegou que a crença testemunhal que um sujeito $S_{1}$ adquiriu de uma testemunha $S_{2}$ não é doxasticamente justificada a menos que o testemunho tomado seja confiável. ${ }^{15}$ Isto, por sua vez, pode depender da confiabilidade do testemunho e, assim, da confiabilidade da formação de crença via este testemunho. Se a testemunha $\mathrm{S}_{2}$ é inconfiável, e assim transmite um testemunho inconfiável, então o receptor do testemunho, $\mathrm{S}_{1}$, pode nem sequer estar doxasticamente justificado em crer no que lhe é dito, segundo essa leitura externalista de justificação.

\footnotetext{
12 Veja Pritchard (2005) e Hetherington (2005) para uma caracterização de sorte epistêmica e Gettierização, respectivamente, em relação à dependência sobre o ambiente no qual um sujeito se encontra.

13 Veja (PRITCHARD, 2012), para uma distinção entre a sorte interveniente e a sorte ambiental, as quais tipificam os casos Gettier em duas categorias e promovem explicações distintas para a ausência de conhecimento em casos que caem sob esses dois tipos.

14 Veja (GOLDBERG, 2010) para uma defesa desse ponto.

15 Veja (LACKEY, 2008).
} 


\section{Dependência epistêmica difusa}

Na seção anterior, vimos que é plausível a tese da dependência epistêmica na versão DIR, isto é, a dependência epistêmica direta. Vimos que os casos de testemunho exemplificam paradigmaticamente tal dependência. Sob uma leitura mais fraca, o conhecimento é um status passível de ser afetado pela perspectiva epistêmica dos outros. Vimos também que sob uma leitura mais forte (neste caso, externalista), inclusive a justificação doxástica da crença testemunhal é passível de ser afetada pela perspectiva epistêmica de outros indivíduos - mais diretamente, a testemunha. Assim, é plausível a tese de que o trabalho cognitivo é distribuído nos casos de testemunho, o que suporta a tese da dependência epistêmica direta encapsulada no princípio DIR exposto anteriormente.

Vamos agora examinar uma segunda forma de dependência epistêmica identificada por Goldberg, a saber, a dependência epistêmica difusa, encapsulada no princípio DIF. Para tanto, ele pede que consideremos o seguinte princípio, aparentemente inocente e óbvio, sobre conhecimento testemunhal:

(*) O fato de que uma pessoa passa ou não a saber por meio de testemunho depende apenas da qualidade epistêmica do testemunho e da qualidade epistêmica da reação do ouvinte ao testemunho. ${ }^{16}$

Aqui, Goldberg explica que este princípio parece inocente e perfeitamente aceitável somente se nós assumimos as seguintes duas hipóteses: (1) as únicas partes relevantes quanto a se um ato de testemunho resulta em conhecimento são as partes envolvidas no próprio ato, e (2) as únicas partes envolvidas em um ato de testemunho são somente a testemunha e o receptor

16 Do original: Whether a person knows through testimony depends only on the epistemic goodness of the testimony and on the epistemic goodness of the hearer's reaction to the testimony (GOLDBERG, 2011, p. 116, tradução nossa). 
(isto é, o falante e o ouvinte). ${ }^{17}$ Ele pretende mostrar que o princípio (*) é falso ao mostrar a falsidade destas duas suposições das quais o princípio depende.

Primeiro, Goldberg considera um exemplo do que chama de casos de "credibilidade de monitoramento distribuída". Esses casos desafiam a suposição (1), de que apenas a testemunha e o receptor figuram a relação de dependência epistêmica nos casos de testemunho. Considere o seguinte exemplo.

Suponha que $S$ testemunha que $P$, em condições nas quais existe um derrotador $\mathrm{D}$ do qual $\mathrm{S}$ não faz ideia, cuja presença faz com que seja um acidente que a crença (e o testemunho) de $\mathrm{S}$ de que $\mathrm{P}$ seja verdadeiro; mas suponha também que $\mathrm{T}$, embora não sabendo de $\mathrm{D}$, tem um papa-derrotador $D^{*}$, tal que dado que $D^{*}$, a verdade do testemunho de $S$ de que $P$ não é meramente acidental. Agora, se $A$ não sabe $D$ e $D^{*}$, mas T é tal que se $D *$ não tivesse se dado, então ela teria alertado $A$ a não aceitar o testemunho de $S$, então novamente a crença testemunhal de A é segura, sensível, e confiavelmente formada - ou ao menos tão sensível, segura, e confiavelmente formada como é a crença de T de que P. ${ }^{18}$

O exemplo acima, além de desabusar-nos do princípio (*) sobre testemunho que estamos considerando, dá-nos uma segunda instanciação de dependência epistêmica direta, a saber, a dependência epistêmica da crença testemunhada em relação a quem está de algum modo conectado ao ambiente no qual o testemunho se dá, e pode intervir caso julgue necessário, livrando o receptor de tomar um mal testemunho. Em casos como

\footnotetext{
17 Cf. GOLDBERG, 2011, p. 116.

18 Do original: So suppose $S$ testifies that $p$, under conditions in which there is a defeater D of which $S$ is unaware, whose obtaining makes it lucky that $S$ 's belief (and testimony) that $p$ is true; but suppose further that $T$, though aware of $D$, has a defeater-defeater $D^{*}$, where given $D^{*}$, the truth of S's testimony that $p$ is not merely lucky. Now if $A$ is ignorant of $D$ and $D^{*}$, but $T$ is such that had $D^{*}$ not obtained she would have cautioned $A$ against accepting $S^{\prime}$ s testimony, then once again A's testimonial belief that $p$ is safe, sensitive, and reliably-formed - or at least as sensitive, safe, and reliably formed as is T's belief that p (GOLDBERG, 2011, p. 117, tradução nossa).
} 
esse, o receptor depende da perspectiva epistêmica deste(s) terceiro(s) - T, no caso recém considerado - para conferir segurança ao testemunho, uma vez que se a perspectiva epistêmica deste terceiro não favorecer o que está sendo dito, ele intervirá e impedirá a ignorância do receptor.

Assim, esta terceira parte, T, na melhor das hipóteses, garante, a qualidade, confiabilidade e segurança da crença testemunhal do receptor, pois dada a sua perspectiva epistêmica, T se manifestaria caso alguma informação falsa, injustificada ou inadequada fosse proferida e tomada pelo receptor.

A suposição (2), da qual o princípio (*) depende também é falsa, segundo Goldberg, e ao mostrar a sua falsidade ele nos apresenta a segunda forma de dependência epistêmica suportando a veracidade da hipótese da divisão do trabalho cognitivo. Este ponto, embora tenha recebido pouca atenção na literatura, é o mais intuitivo. Parte-se de uma constatação bastante banal: o risco epistêmico de tomar um testemunho em certos contextos é maior do que em outros, e isto depende não apenas da testemunha que o profere, mas de como a comunidade epistêmica o "monitora”, por assim dizer.

A típica brincadeira infantil "Telefone sem fio" ilustra esse ponto. À medida que a mensagem passe de um para outro na cadeia testemunhal, o risco de se ganhar uma informação não acurada aumenta. Em contrapartida, em comunidades epistêmicas vigilantes, epistemicamente falando, as informações propagadas tendem a ser filtradas pelos demais membros, por meio das suas perspectivas epistêmicas. Como um resultado disso, se alguma dissonância é dubitável, o elo da cadeia testemunhal que a detecta não segue transmitindo o testemunho; antes, ele alerta os demais membros da comunidade quanto a sua possível não acurácia.

Se Ana, por exemplo, vive em uma comunidade epistemicamente vigilante, a confiabilidade do processo de formação de crenças via testemunho que ela emprega é alta, e as suas crenças testemunhais tendem a ser casos de conhecimento. O mesmo se aplica à segurança dessas crenças, uma vez que em situações contrafactuais próximas, se ela crê via testemunho, no mais das vezes ela crerá verazmente. Se Sara, por exemplo, ao contrário de Ana, vive em uma comunidade epistemicamente pobre, 
o monitoramento dos membros da sua comunidade não contribuirá nem para a confiabilidade nem para a segurança das suas crenças testemunhais.

Por fim, notemos que o papel de monitoramento da credibilidade de testemunhos não é uma terceira parte no contexto de testemunho, mas algo externo ao ato testemunhal que, ainda assim, incide sobre o seu status epistêmico. Isso mostra que a suposição (2) é falsa e, ao mesmo tempo, exemplifica a dependência epistêmica difusa.

\section{Dependência epistêmica e os casos sociais tipo-Gettier de Gilbert Harman}

Considere o seguinte caso tipo-Gettier que, segundo Gilbert Harman (1973), difere dos típicos casos tipo-Gettier por revelar uma suposta dimensão social do conhecimento:

[Os Jornais]: Um líder político é assassinado. Os seus companheiros, temendo um golpe, decidem fingir que a bala atingiu outra pessoa. Em rede nacional, eles anunciam que a tentativa de assassinato não matou o líder, mas matou, por engano, um homem do serviço secreto. Contudo, antes que o anúncio fosse feito, um esperto repórter que estava na cena do crime, telefona ao jornal contando a verdadeira história, que o jornal incluiu na sua edição final. Jill compra uma cópia daquele jornal e lê a história do assassinato. O que ela lê é verdadeiro, e assim também são as suas suposições sobre como a história apareceu no jornal. O repórter, cuja assinatura aparece no jornal, viu o assassinato e ditou o seu relato, que agora está impresso como ele o ditou. Jill tem crença verdadeira justificada e, ao que parece, tem, igualmente, todas as suas conclusões intermediárias verdadeiras. Mas, ela não sabe que o líder político foi assassinado. Afinal, todas as outras pessoas ouviram o anúncio na televisão. Até pode ser que elas tenham visto a história no jornal impresso e 
talvez não saibam no que acreditar; e é altamente implausível que Jill deveria saber simplesmente porque ela não tem a evidência que todas as outras pessoas têm. Jill não sabe. Seu conhecimento é solapado pela evidência que ela não possui.. ${ }^{19}$

Então Jill não sabe que o líder político foi assassinado só porque todos em torno dela têm contraevidência para acreditar naquilo? Harman nega conhecimento para Jill, como recém vimos. Nozick faz o mesmo, por meio da inclusão de uma condição de aderência para a aquisição de conhecimento -- segundo a qual se $S$ sabe que $P$, então se $P$ fosse verdadeiro, e $S$ considerasse a questão de se $\mathrm{P}$, então $\mathrm{S}$ acreditaria que $\mathrm{P}^{20}$ Harman nega conhecimento para Jill porque acredita que ela se encontra em um ambiente epistêmico que a impede de obter conhecimento. Afinal, todas as outras pessoas estão sob o efeito solapador da transmissão do anúncio negando o assassinato do líder político, e elas já não acreditam que ele foi assassinado. $O$ aspecto social do conhecimento que esse caso supostamente revela é justamente esse que interfere na avaliação de um status epistêmico com base no que as outras pessoas no seu ambiente sabem, creem, ou tem como evidência.

A divisão do trabalho epistêmico é importante para detectarmos se Jill adquire conhecimento ou não. Como Goldberg, vamos procurar entender esse fenômeno em termos da dependência epistêmica de Jill

\footnotetext{
19 Do original: A political leader is assassinated. His associates, fearing a coup, decide to pretend that the bullet hit someone else. On nationwide television they announce that an assassination attempt has failed to kill the leader but has killed a secret service man by mistake. However, before the announcement is made, an enterprising reporter on the scene telephones the real story to his newspaper, which has included the story in its final edition. Jill buys a copy of that paper and reads the story of the assassination. What she reads is true and so are her assumptions about how the story came to be in the paper. The reporter, whose by-line appears, saw the assassination and dictated his report, which is now printed just as he dictated it. Jill has justified true belief and, it would seem, all her intermediate conclusions are true. But she does not know that the political leader has been assassinated. For everyone else has heard about the televised announcement. They may also have seen the story in the paper and, perhaps, do not know what to believe; and it is highly implausible that Jill should know simply because she lacks evidence everyone else has. Jill does not know. Her knowledge is undermined by evidence she does not possess (HARMAN, 1973, p. 143-144, tradução nossa).

20 Veja Nozick (1981, p. 177) para o tratamento do caso "Os Jornais por meio da condição de aderência".
} 
em relação aos outros. O princípio DIR, de dependência epistêmica direta, orienta-nos a olhar para a confiabilidade da fonte que testemunhou a notícia sobre o líder político para Jill, a saber, o jornal local. Jill tomou o seu testemunho enquanto o jornal ainda era confiável, pois não havia qualquer suspeita sobre manipulação do que era publicado. No entanto, a crença verdadeira de Jill não era segura, porque no mundo mais próximo (a saber, o mundo atual horas depois), se ela passasse a crer nas notícias que leria, ela acabaria crendo falsamente. Jill não parece ter conhecimento.

Tendo em mente o princípio DIF, dependência epistêmica difusa, somos orientados a olhar para o papel que a comunidade de Jill desempenha no monitoramento da credibilidade do testemunho que circula por lá. Aqui, o veredito de ignorância de Jill é dado mais confiantemente. Pois na comunidade de Jill, a maioria dos indivíduos encontram-se enganados sobre a situação do líder político; e o que é pior, eles encontram-se sem condições de discriminar entre bom e mau testemunho do jornal local. A comunidade de Jill, nesta circunstância, é incapaz de lhe garantir confiabilidade ou segurança. Assim, por meio de mais um experimento, Jill não parece ter conhecimento - e são considerações sobre a divisão do trabalho epistêmico que nos levam a esta conclusão.

\section{Considerações finais}

Neste ensaio nós examinamos a proposta de Sandy Goldberg, segundo a qual há divisão de trabalho epistêmico em certos processos de aquisição de conhecimento. Nós vimos que essa ideia é suportada pela dependência epistêmica que temos em relação a outros sujeitos ou mesmo comunidades. Vimos que há dois tipos de dependência epistêmica, a saber, a direta e a difusa. A primeira é evidenciada na interação entre testemunha e receptor, e a segunda é evidenciada pelo assim-chamado monitoramento de credibilidade exercido pela comunidade na qual se está inserido. Por fim, nós aplicamos essas ideias na avaliação de um caso tipo-Gettier que revela certa dimensão social do conhecimento. Nossa conclusão é que (i) claramente há 
divisão do trabalho epistêmico na aquisição de conhecimento testemunhal, que (ii) a ideia de dependência epistêmica ajuda-nos a explicar em que sentido a aquisição de conhecimento naqueles casos não depende só do sujeito, e (iii) que isso demonstra como o conhecimento é mais social do que individual em se tratando de uma ampla gama de casos.

\section{Referências}

AUDI, R. The Place of Testimony in the Fabric of Justification and Knowledge. American Philosophical Quarterly, Bowling Green (OH), v. 34, p. 405-422, 1997. BECKER, K. Epistemology Modalized. New York: Routledge, 2007.

FELDMAN, R.; CONEE, E. Internalism Defended. American Philosophical Quarterly, Bowling Green (OH), v. 38, n. 1, p. 1-18, 2001.

GOLDBERG, S. Relying on Others: An Essay in Epistemology. Oxford: Oxford University Press, 2010. https://doi.org/10.1093/acprof:oso/9780199593248.001.0001

GOLDBERG, S. The Division of Epistemic Labor. Episteme, [S. I.], v. 8, n. 1, p. 112-125, 2011.

GOLDMAN, A. Discrimination and perceptual knowledge. Journal of Philoysophy, New York (NY), v. 73, p. 771-791, 1976. https://doi.org/10.2307/2025679

HARMAN, G. Thought. Princeton: Princeton University Press, 1973.

HETHERINGTON, S. Gettier problems. Internet Encyclopedia of Philosophy, 2005. KLEIN, P. Certainty: a Refutation of Scepticism. University of Minnesota Press, 1981.

KLEIN, P. What Makes Knowledge the Most Highly Prized Form of True Belief. In: BECKER, K.; BLACK, T. The Sensitivity Principle in Epistemology. Cambridge: Cambridge University Press, 2012. p. 152-169. https://doi.org/10.1017/ cbo9780511783630.012

LACKEY, J. Learning from Words: Testimony as a Source of Knowledge. Oxford: Oxford University Press, 2008. https://doi.org/10.1093/acprof:0so/9780199219162.001.0001

NOZICK, R. Philosophical Explanations. Harvard University Press, 1981. 
PRITCHARD, D. Epistemic Luck. New York: Oxford University Press, 2005. https://doi.org/10.1093/019928038X.001.0001

PRITCHARD, D. Anti-Luck Virtue Epistemology. Journal of Philosophy, New York, v. 109, n. 3, p. 247-279, 2012. https://doi.org/10.5840/jphil201210939 SOSA, E. How to defeat opposition to Moore. Philosophical Perspectives, Malden, Mass., v. 13, p. 137-149, 1999a. https://doi.org/10.1111/0029-4624.33.513.7

\section{Endereço postal}

J. R. Fett

Pontifícia Universidade Católica do Rio Grande do Sul - (PUCRS)

Programa de Pós-Graduação em Filosofia

Av. Ipiranga, 6681.

CEP 90.619-900 - Partenon, Porto Alegre, RS - Brasil. 